\title{
Pienten porsaiden mahahaava
}

Maija Karhapää ja Kirsi Partanen

Maa- ja elintarviketalouden tutkimuskeskus MTT, Kotieläintuotannon tutkimus, Tervamäentie 179, 05840 Hyvinkää, maija.karhapaa@mtt.fi, kirsi.partanenen@mtt.fi

\section{Tiivistelmä}

Pyrkimys alentaa vieroitusikää ja kasvattaa pahnuekokoa voi aiheuttaa ongelmia. Emakolla tulisi olla riittävästi toimivia nisiä kaikille porsaille, muuten imetystilanne on rauhaton. Lisäruokinta on aloitettava varhain, vaikka porsaiden ruoansulatuselimistö ei ole vielä täysin kehittynyt sulattamaan kiinteää ja pääosin kasviperäistä rehua. Pikkuporsaille tarkoitetut täysrehut ovat pienirakeista, paljon valkuaista ja erilaisia haju- ja makuaineita sisältäviä, mutta onko niiden hyvin runsas syönti imeväisikäiselle porsaalle kaikilta osin hyväksi? Aikaisemmassa tutkimuksessamme mahahaavaisia porsaita oli enemmän pahnueissa, joissa porsaat söivät enemmän totutusrehua pahnueaikana.

Tässä tutkimuksessa porsaat saivat 10 päivän iästä lähtien totutusrehuina joko kaupallista rakeistettua prestartterirehua tai jauhomaista vilja-puolitiivisteseosta, joka on tarkoitettu käytettäväksi vasta vieroituksen jälkeen. Oletuksena oli, että vilja-tiivistepohjainen porsasrehu jauhomaisena voisi olla parempi vaihtoehto mahanterveyden kannalta kuin rakeistettu porsasrehu. Mahanterveyttä tutkittiin vieroitetulla ja välitysikäisillä porsailla. Kokeessa seurattiin myös porsaiden tuotantotuloksia pahnueaikana ja välikasvattamossa, missä vilja-puolitiivisteseos pysyi samana ja prestartteri vaihdettiin rakeistettuun porsasrehuun.

Pahnueaikana ja heti vieroituksen jälkeen porsaat söivät vilja-puolitiiviste-rehua vähemmän kuin rakeista porsasrehua ja vilja-puolitiiviste-rehua syöneet porsaat kasvoivat myös hieman huonommin kuin rae-rehua syöneet porsaat. Vilja-puolitiiviste ruokinnan pahnueissa oli tosin keskimäärin puolitoista porsasta enemmän imetettävänä kuin raemaisella ruokinnalla. Välikasvatusvaiheessa viljapuolitiiviste-rehulla ruokittaessa porsaiden kasvu ja rehuhyötysuhde olivat merkitsevästi parempia kuin raemaisella rehulla ruokittaessa.

Aikaisemmissa kokeissa olemme todenneet, että kipua aiheuttavia mahahaavoja on paljon jo välitysikäisillä porsailla (39 \%, $n=64)$. Tässä kokeessa vieroitusikäisillä porsailla $(n=66)$ mahalaukun limakalvovaurioita oli enemmän rakeista prestartteria syöneillä porsailla, kuin jauhorehua syöneillä porsailla (76 vs. $52 \%, \mathrm{p}=0,04)$. Välitysikäisillä porsailla $(\mathrm{n}=66)$ ryhmien välillä ei ollut merkitsevää eroa, mutta sielläkin rakeista rehua syöneillä porsailla mahalaukun limakalvomuutoksia oli määrällisesti enemmän kuin vilja-tiivisterehua syöneillä porsailla (67 vs. $52 \%$ ).

Tulosten perusteella jo vieroitusikäisillä porsailla on huomattavan paljon mahalaukun limakalvomuutoksia, jotka edetessään mahahaavaksi aiheuttavat kipua porsaille. Jauhomainen rehu vaikuttaisi olevan porsaiden mahanterveyden kannalta parempi vaihtoehto. Vilja-puolitiivisteruokinta ei ollut porsaiden kasvun kannalta juurikaan huonompi vaihtoehto ja rehuhyötysuhde oli välikasvatuksessa vilja-puolitiiviste-ruokinnalla jopa hieman parempi kuin raeruokinnalla.

Asiasanat: mahahaava, porsas, ruokinta 


\section{Johdanto}

Nykyisin lisärehua tarjotaan jo muutaman päivän ikäisille porsaille, koska pahnuekoot ovat kasvaneet ja vieroitusikä halutaan pitää mahdollisimman alhaalla. Pikkuporsasrehun tarkoituksena on totuttaa porsaita jo imetysaikana kuivalle rehulle, joka auttaa porsaita vieroitusvaiheessa. Kaupalliset pikkuporsaille tarkoitetut prestartterirehut ovat pienirakeisia ja ne sisältävät usein erilaisia haju- ja makuaineita, joiden tarkoituksena on houkutella imevät porsaat syömään kiinteää rehua mahdollisimman varhain ja mahdollisimman paljon. Näin varhaisessa iässä porsaiden ruoansulatuselimistö ei ole vielä täysin kehittynyt sulattamaan kiinteää, kasviperäistä rehua. Voiko varhainen lisärehun syöminen aiheuttaa vaurioita mahalaukun limakalvolle? Aikaisemmassa kokeessa, pahnueissa joissa oli enemmän mahahaavaisia porsaita, oli suurempi lisärehun kulutus pahnueaikana (Karhapää ym. 2009).

Kivuntunnetta aiheuttava mahahaavauma on hyvinvointiongelma, jota esiintyy kaikenikäisillä sioilla. Sikojen mahahaavan arvellaan johtuvan useiden tekijöiden yhteisvaikutuksesta. Rehun raakaainekoostumus, olomuoto, rakeen laatu ja viljan jauhatusaste ovat seikkoja, jotka todennäköisesti vaikuttavat mahahaavan syntymiseen. Rehun rakeistus on riskitekijä mahahaavan syntymiselle (Nielsen ja Ingvartsen 2000, Robertson ym. 2002). Rakeistuksen katsotaan vastaavan yhtä jauhatuskertaa. Liian hienojakoinen aines porsasrehussa aiheuttaa mahansisällön sekoittumisen, jolloin hapot polttavat herkkää mahanportin aluetta ja haavaumariski kasvaa (Nielsen ja Ingvartsen 2000). Gamblen ym. (1967) mukaan sioilla, jotka olivat syöneet rakeistettua rehua sekä ennen vieroitusta että myöhemmin, esiintyi mahahaavoja merkitsevästi enemmän kuin jauhomaista rehua saaneilla sioilla. Viljatiivistepohjainen porsasrehu jauhomaisena voisi olla parempi vaihtoehto mahanterveyden kannalta kuin rakeistettu porsasrehu. Pikkuporsaiden ensimmäisenä rehuna ei juuri käytetä vilja-tiivisteseoksia, koska niitä ei saada yhtä väkeviksi prestartteri-täysrehuihin verrattuna, ja kasvu on siksi hitaampaa. Toisaalta pikkuporsaiden ruokinnan yksinkertaistaminen ei välttämättä vaikuta sikojen kasvuun, kun tarkkailujaksona on koko lihasian kasvatusjakso teuraspainoon saakka (Chiba 1994).

Tutkimuksen tarkoituksena oli selvittää esiintyykö porsailla mahahaavaa tai siihen viittaavia muutoksia vieroituksessa tai välikasvatuksen jälkeen ja vaikuttaako totutusrehun laatu mahalaukun limakalvovaurioiden esiintymiseen. Kokeessa verrattiin rakeistetun pikkuporsaiden prestartterirehun (myöhemmin rakeistettu rehu) ja vilja-puolitiivisteseoksen vaikutusta porsaiden kasvuun, ripulin esiintymiseen ja mahan terveyteen. Mahahaavojen esiintymistä selvitettiin porsaita lopettamalla.

\section{Aineisto ja menetelmät}

Koe tehtiin satunnaistettujen lohkojen kokeena, missä syntyneet pahnueet (24 pahnuetta, yhteensä 332 porsasta) jaettiin porsituserän sisällä pahnueen rodun ja emakon porsimakerran perusteella mahdollisimman samankaltaisiin pareihin. Kunkin parin sisällä pahnueet arvottiin kahteen ruokintakäsittelyyn, joissa porsaiden rehuna käytettiin joko 1) vilja-puolitiivisteseosta (vehnä, ohra, kaura ja Oy Feedex Ab:n Teho Atlet -puolitiiviste) tai 2) kaupallista, rakeistettua pikkuporsaiden täysrehua (Suomen Rehu Oy:n Pikku-Pekoni prestartterirehu), joka välikasvatusosastolle siirrettäessä vaihdettiin MTT:llä valmistettuun rakeistettuun porsasrehuun. Vilja-puolitiivisteseos pysyi samana koko kasvatusajan. Imeville porsaille tarjottiin rehua 10 päivän ikäisestä alkaen PlayFeeder -kaukalosta, jonka pohjalla on nisien kaltaiset ulokkeet. Myöhemmin rehu tarjottiin vapaasti automaateista.

Kokeessa oli 2. - 8. kertaa porsineiden emakoiden pahnueita. Vilja-puolitiiviste ruokinnan ryhmässä Duroc-risteytysporsaita oli $41 \%$ ja raeruokinnan ryhmässä $47 \%$ ja loput olivat valkoisten rotujen (maatiainen, yorkshire ja norjanmaatiainen) risteytyksiä. Pahnueiden tasaus tehtiin kahden vuorokauden kuluessa porsimisesta. Kokeeseen otetuissa pahnueissa tuli olla vähintään 8 imetettävää porsasta (omat ja tasatut) 3 päivää porsimisen jälkeen. Porsimaosastolla tallennettiin videokuvaa nisäjärjestyksen ja syömään oppimisen selvittämiseksi.

Mahahaavaisten porsaiden esiintymistä arvioitiin porsaita lopettamalla vieroituksen yhteydessä ja välityskokoisilla porsailla. Lopetettavat porsaat valittiin nisäpaikan perusteella. Nisäpaikka määritettiin videotallenteelta kahden päivän tarkkailujaksolta noin viikko ennen vieroitusta, jolloin porsaan nisäpaikka jokaisessa imetyksessä (päiväsaikaan) kirjattiin ylös. Nisäpaikan perusteella pahnueesta arvottiin yhteensä kolme porsasta lopetettavaksi vieroitettaessa. Päänpuolen nisäparilta arvottiin toinen porsas lopetettavaksi vieroitettaessa ja samoin toinen porsas takapään nisäparilta, sekä lisäksi yksi sika arvottiin nisäjärjestyksen mukaan keskellä olleista porsaista. Välikasvatusvaiheen lopussa lopetettiin porsas etupään ja takapään nisäparilta, minkä lisäksi karsinasta arvottiin kolmas porsas lopetettavaksi. 
Mahalaukun limakalvomuutokset arvioitiin silmämääräisesti ruokatorvi- ja rauhasalueelta neliportaisella asteikolla (Hautala ja Rautiainen 1991).

Kaikki samassa porsitusosastossa syntyneet porsaat vieroitettiin samana päivänä. Vieroitettaessa emakot siirrettiin tiineytysosastolle ja porsaat jäävät porsituskarsinoihin yhtenäisinä pahnueina vielä viikoksi, minkä jälkeen osalla porsaista koe jatkui välikasvatusosastolla, pääsääntöisesti yksi neljän sian karsina. Kahdesta pahnueesta jatkoi kaksi neljän porsaan karsinaa. Välikasvatusosastolla jatkavista porsaista kaksi oli nisäjärjestyksen mukaan alku- ja loppupään nisäparin eloon jäänyt porsas (toinen porsas lopetettiin mahahaavan arvioimista varten) ja näiden lisäksi arvottiin kaksi sikaa pahnueen jäljelle jääneistä yli $7 \mathrm{~kg}$ painavista porsaista.

Porsaat punnittiin syntymäpäivänä, lisäruokinnan alkaessa (10 pv iässä), vieroituksessa ja viikko vieroituksen jälkeen. Pahnueesta välikasvatusosastolla jatkaneet porsaat punnittiin rehun vaihtuessa sekä kokeen päättyessä porsaiden ollessa noin 21 kilon painoisia (noin 8 viikon ikäisiä). Vastaavilta jaksoilta määritettiin myös rehunkulutus pahnue-tai karsinakohtaisesti. Ripulin esiintymistä ja ulosteen kiinteyttä tarkkailtiin vieroituksen jälkeen päivittäin karsinakohtaisesti hoitotoimien yhteydessä.

Viljoista ja valmiista rehuseoksista otettiin rehunäytteet, joista tehtiin rehuanalyysi, analysoitiin kivennäispitoisuudet ja rehuseoksista myös detergenttikuidut ja ligniini.

Tulosten tilastollinen analysointi tehtiin SAS-ohjelmiston MIXED ohjelmalla. Kasvun, rehunkulutuksen, rehuhyötysuhteen ja ripulihavaintojen havaintoyksikkönä oli karsina. Mahalaukkumuutosten ja kasvujen havaintoyksikkönä oli yksittäinen sika. Aineiston analysoimiseen käytettiin mallia, jossa olivat mukana emakkoparin satunnainen vaikutus ja porsitusryhmän ja käsittelyn kiinteät vaikutukset sekä näiden yhdysvaikutukset. Porsaiden kasvuja analysoitaessa virhetekijänä oli pahnue. Pahnueaikaisen päiväkasvun analysoinnissa käytettiin kovariaattina emakon imettämien porsaiden lukumäärää sekä porsaiden syntymäpainoa. Välikasvatusvaiheen kasvujen analysoinnissa käytettiin kovariaattina porsaiden kasvua imetysaikana. Yhdysvaikutuksia oli tästä huolimatta, eikä aineiston normaalisuus oletus täysin toteutunut. Asteikolla luokitellut muuttujat analysoitiin $\chi 2$-testillä.

\section{Tulokset ja tulosten tarkastelu \\ Rehujen kemiallinen koostumus}

Koerehujen analysoitu koostumus on esitetty taulukossa 1. Kaupallinen rakeistettu prestartterirehu sisälsi selvästi enemmän raakarasvaa ja huomattavasti vähemmän kuituja (NDF ja ligniini) kuin viljapuolitiivisteseos. Prestartterirehun kuparipitoisuus oli huomattavasti korkeampi kuin muissa rehuissa. Rehun korkea kuparipitoisuus on sikoja mahahaavaumille altistava tekijä (Ritchie ym. 1963).

Taulukko 1. Koerehujen analysoitu koostumus.

\begin{tabular}{lcccc}
\hline \hline & $\begin{array}{c}\text { Vilja-puoli- } \\
\text { tiiviste }\end{array}$ & $\begin{array}{c}\text { Pre- } \\
\text { startteri }\end{array}$ & $\begin{array}{c}\text { Välikasvatus 1 } \\
100\end{array}$ & $\begin{array}{c}\text { Välikasvatus 2 } \\
101\end{array}$ \\
\hline \hline Analysoitu koostumus $(\mathrm{g} / \mathrm{kg} \mathrm{ka})$ & & & & \\
Raakavalkuainen & 210 & 211 & 208 & 192 \\
Raakarasva & 41 & 98 & 53 & 50 \\
Raakakuitu & 39 & 35 & 34 & 57 \\
Kalsium & 9,6 & 8,0 & 9,6 & 9,4 \\
Magnesium & 2,6 & 2,0 & 2,1 & 2,0 \\
Fosfori & 6,8 & 7,4 & 7,1 & 7,0 \\
Rikki & 2,5 & 3,6 & 2,3 & 2,0 \\
Kalium & 6,9 & 7,5 & 7,2 & 8,1 \\
Natrium & 2,1 & 2,6 & 1,5 & 1,0 \\
Rauta & 347 & 360 & 309 & 288 \\
Kupari & 79 & 182 & 31 & 3 \\
Sinkki & 179 & 165 & 126 & 105 \\
Mangaani & 67 & 72 & 63 & 43 \\
NDF & 159 & 126 & 145 & 148 \\
ADF & 49 & 41 & 49 & 46 \\
Ligniini & 1,7 & 0,4 & 2,4 & 0,0 \\
\hline \hline
\end{tabular}




\section{Porsaiden kasvu ja rehunkulutus}

Kokeen emakoiden keskimääräinen porsimakerta oli vilja-puolitiivisteruokinta ryhmässä 4,2 (vaihtelu 2-8) ja raeruokintaryhmässä 3,6 kertaa (vaihtelu 2-8). Vilja-puolitiivisteruokinta ryhmässä pahnuekoko oli tasauksen jälkeen suurempi kuin rae-ruokinta ryhmässä (11,9 vs. 10,5 porsasta). Myös vieroitettujen porsaiden määrä oli vilja-puolitiivisteruokinta ryhmässä 1,5 porsasta suurempi kuin raeruokintaryhmässä (11,8 vs. 10,3). Porsaiden keskimääräinen vieroitusikä oli 25 päivää (22-27 päivää).

Pahnueen porsaiden keskimääräinen syntymäpaino oli $1,7 \mathrm{~kg}$ molemmissa ruokintaryhmissä (Taulukko 2). Raeruokintaryhmän porsaat painoivat vieroituksessa ja viikon kuluttua vieroituksesta enemmän kuin vilja-puolitiivisteruokintaryhmän porsaat $(\mathrm{p}=0,004 \mathrm{ja} \mathrm{p}<0,001)$. Raeruokintaryhmän porsaat olivat keskimäärin $0,9 \mathrm{~kg}$ painavampia vieroituksessa, kuin vilja-puolitiivisteruokitut porsaat (Taulukko 2). Rae-ruokinta ryhmän porsaiden keskimääräinen päiväkasvu vieroituksen jälkeisellä viikolla oli parempi kuin vilja-puolitiivisteruokituilla porsailla (54 vs. $125 \mathrm{~g} / \mathrm{pv}$; $\mathrm{p}<0,001$ ).

Taulukko 2. Porsaiden kasvu pahnueaikana.

\begin{tabular}{|c|c|c|c|c|c|}
\hline \multirow[t]{2}{*}{ Koekäsittely } & \multicolumn{2}{|c|}{ Vilja-puolitiiviste-rehu } & \multicolumn{2}{|c|}{ Rae-rehu } & \multirow[b]{2}{*}{$\mathrm{P}$} \\
\hline & Keskiarvo & SEM & Keskiarvo & SEM & \\
\hline Pahnueita & 12 & & 12 & & \\
\hline \multicolumn{6}{|l|}{ Paino, $\mathrm{kg}$} \\
\hline Syntymä (1 pv) & 1,7 & 0,04 & 1,7 & 0,04 & \\
\hline Rehun antaminen (10 pv) & 3,9 & 0,11 & 4,2 & 0,11 & \\
\hline Vieroitus (n. 25 pv) & 8,4 & 0,17 & 9,3 & 0,18 & $* *$ \\
\hline Viikko vieroituksesta & 8,7 & 0,16 & 10,2 & 0,18 & $* * *$ \\
\hline \multicolumn{6}{|l|}{ Päiväkasvu, g } \\
\hline Syntymä-rehun antaminen (10 pv) & 229 & 10,2 & 232 & 11,2 & \\
\hline Rehun antaminen-vieroitus & 317 & 7,5 & 337 & 8,2 & \\
\hline Imetysaika yhteensä & 282 & 6,6 & 296 & 7,2 & \\
\hline Vieroituksen jälkeinen viikko & 54 & 7,2 & 125 & 7,7 & $* * *$ \\
\hline
\end{tabular}

Pahnueaikana porsaat söivät vilja-puolitiiviste ryhmässä vähemmän lisärehua päivässä kuin raeruokintaryhmän porsaat $(0,02$ vs. $0,03 \mathrm{ry} /$ porsas $/ \mathrm{pv} ; \mathrm{p}=0,003)$. Rehumäärään vaikutti merkitsevästi vieroitusryhmä ja ruokintaryhmän ja vieroitusryhmän välillä oli myös yhdysvaikutus. Vieroituksen jälkeisellä viikolla rae-rehua syöneet porsaat söivät enemmän rehua kuin viljapuolitiivisteruokintaryhmän porsaat $(0,16$ vs. $0,23 \mathrm{ry} /$ porsas $/ \mathrm{pv} ; \mathrm{p}<0,001)$. Syödyn rehun määrään vaikutti myös vieroitusryhmä merkitsevästi. Algers ym. (1989) mukaan ne pahnueen porsaat, joiden paino oli noussut eniten viikoilla 3-4 porsimisen jälkeen (hyvä nisäpaikka), söivät vähemmän lisärehua ja joivat vähemmän vettä kuin pahnuetoverit ennen vieroitusta. Näiden porsaiden suhteellinen kasvu kuitenkin taantui vieroituksen jälkeen, koska ne eivät olleet tottuneet syömään lisärehua eivätkä kilpailemaan ruokintapaikalla.

Koetta jatkaneet raeruokintaryhmän porsaat olivat välikasvatusosastolle siirtyessä ja ensimmäisessä rehunvaihdossa merkitsevästi painavampia kuin vilja-puolitiivisteruokitut porsaat (Taulukko 3). Näissä oli yhdysvaikutus käsittelyn ja vieroitusryhmän välillä. Välikasvatusosastolla viljapuolitiiviste-ruokinnalla olleet porsaat kasvoivat nopeammin kuin rae-ruokintaryhmän porsaat $(\mathrm{p}=0,04)$. Kasvuun vaikutti merkitsevästi vieroitusryhmä ja ensimmäisessä vaiheessa oli myös yhdysvaikutus vieroitusryhmän ja käsittelyn välillä.

Päivää kohti lasketuissa välikasvatusvaiheen porsaiden rehunsyönneissä ei ollut merkitsevää eroa ruokintaryhmien välillä. Porsaat söivät välikasvatuksen ensimmäisellä kasvatusjaksolla (rehuyksikköinä) enemmän rakeistettua rehua kuin jauhomaista rehua ( 0,52 vs. 0,56 ry/porsas/pv, Taulukko 3). Toisella kasvatusjaksolla molempien ruokintaryhmien porsaat söivät rehuyksikköinä melkein yhtä paljon rehua (0,97 vs. 0,99 ry/porsas/pv), joten koko välikasvatusajan rehunsyönneissä ei juuri ollut eroa $(0,77$ vs. $0,80 \mathrm{ry} /$ porsas/pv). Vieroitusryhmän vaikutus välikasvatusajan rehunsyöntimääriin oli merkitsevä. 
Taulukko 3. Porsaiden kasvu, rehumäärät ja rehuhyötysuhde välikasvatusosastolla.

\begin{tabular}{|c|c|c|c|c|c|}
\hline \multirow[t]{2}{*}{ Koekäsittely } & \multicolumn{2}{|c|}{ Vilja-puolitiiviste-rehu } & \multicolumn{2}{|c|}{ Rae-rehu } & \multirow[b]{2}{*}{$\mathrm{P}$} \\
\hline & Keskiarvo & SEM & Keskiarvo & SEM & \\
\hline Karsinoita & 13 & & 13 & & \\
\hline \multicolumn{6}{|l|}{ Paino, kg } \\
\hline Siirto välikasvatusosastolle & 9,3 & 0,20 & 10,6 & 0,20 & $* * *$ \\
\hline Rehun vaihto & 12,6 & 0,29 & 13,7 & 0,29 & $*$ \\
\hline Lopussa & 20,4 & 0,45 & 21,4 & 0,45 & \\
\hline \multicolumn{6}{|l|}{ Päiväkasvu, g } \\
\hline Vaihe 1 (11 pv) & 312 & 13,0 & 275 & 12,8 & o \\
\hline Vaihe 2 (14 pv) & 573 & 15,7 & 529 & 15,5 & o \\
\hline Välikasvatus yhteensä & 458 & 12,1 & 417 & 12,0 & $*$ \\
\hline \multicolumn{6}{|l|}{ Rehua, (ry/porsas/pv) } \\
\hline Vaihe 1 (11 pv) & 0,52 & 0,023 & 0,56 & 0,023 & \\
\hline Vaihe 2 (14 pv) & 0,97 & 0,023 & 0,99 & 0,023 & \\
\hline Välikasvatus yhteensä & 0,77 & 0,020 & 0,80 & 0,020 & \\
\hline \multicolumn{6}{|c|}{ Rehuhyötysuhde (ry/kg kasvua) } \\
\hline Vaihe 1 (11 pv) & 1,75 & 0,089 & 2,10 & 0,089 & $*$ \\
\hline Vaihe 2 (14 pv) & 1,77 & 0,038 & 1,85 & 0,038 & \\
\hline Välikasvatus yhteensä & 1,75 & 0,037 & 1,90 & 0,037 & $*$ \\
\hline
\end{tabular}

Rehuhyötysuhde oli molemmilla välikasvatuksen jaksoilla parempi vilja-puolitiivisteruokituilla porsailla (Taulukko 3). Ero oli merkitsevä ensimmäisessä kasvatusvaiheessa ja tarkasteltaessa koko välikasvatusvaihetta. Vieroitusryhmän vaikutus oli merkitsevä (paitsi vaihe 1) ja käsittelyn ja vieroitusryhmän välillä oli yhdysvaikutus. Rehun tuhlaushavaintoja oli enemmän ensimmäisessä ruokintavaiheessa ja enemmän raeruokinnan karsinoissa kuin jauhomaisella ruokinnalla (4 vs.1 kpl). Tuhlaantunut rehu pyrittiin arvioimaan silmämääräisesti ja se on vähennetty syödystä rehumäärästä, mutta tästä huolimatta on mahdollista, että rehun tuhlaus on syynä raeruokinnan huonompaan rehuhyötysuhteeseen.

Porsailla oli tavallista vähemmän vieroitusripulihavaintoja. Osittain tähän voi vaikuttaa se, että porsaat jäivät vieroituksen jälkeen vielä viikoksi porsimakarsinoihin ennen välikasvatusosastolle siirtymistä. Heti vieroituksen jälkeen ripulihavaintoja oli enemmän vilja-puolitiivisteruokituilla porsailla (14 vs. 5 ripulipäivää). Porsaiden siirryttyä välikasvatusosastolle, rae-rehuryhmän rehu muuttui rakeistetusta prestartterirehusta rakeistettuun porsasrehuun ja tällöin rae-rehuruokinnan karsinoissa oli enemmän ripulihavaintoja ( 15 vs. 27 pv). Tosin, vaikka rehu vaihtui rae-ruokintaryhmässä myös välikasvatusjakson puolivälissä, ripulipäiviä oli yhtä vähän molemmissa ruokintaryhmissä (10 vs. 11 pv). Ripulin hoitoon tarkoitettua ravintoliuosta tai lääkettä ei tarvinnut käyttää yhdessäkään karsinassa.

\section{Mahahaavamuutokset}

Sikojen mahahaavan arvellaan johtuvan useiden tekijöiden yhteisvaikutuksesta. Tällaisia ovat mm. hienoksi jauhetun rehuviljan käyttö, sikojen kokema stressi ja muut sairaudet. Mahahaavamuutosten indikointi on vaikeaa, koska mahahaavamuutokset eivät yleensä vaikuta sikojen kasvuun tai rehuhyötysuhteeseen (Wondra ym. 1995, Guise ym. 1997). Mahahaavat aiheuttavat kuitenkin porsaille kipua ja riskinä on menettää koko porsas mahahaavan puhjetessa. Tällöin porsas löydetään kuolleena ja porsaan kalpeus on ainut päällepäin näkyvä sairauden oire. Akuutissa mahahaavassa oireita ovat ruokahaluttomuus, juomattomuus, heikotus, anemia ja musta tervainen uloste. Ilmeisesti mahahaava paranee monesti itsestään, jolloin jäljelle jää arpikudosta. Monta kertaa uusiutunut mahahaava mahanportin alueella voi aiheuttaa kurouman, jolloin porsas oksentelee ja sen kasvu pysähtyy.

Vilja-puolitiivisteruokinta vaikuttaisi olevan porsaille parempi vaihtoehto mahanterveyden kannalta kuin raemainen ruokinta. Vieroitusikäisillä vilja-puolitiivisteruokituilla porsailla oli huomattavasti enemmän normaaleja, terveitä mahalaukkuja kuin raeruokituilla porsailla ( 48 vs. $24 \%, p=0,04$ ). Vieroitusikäisistä avatuista porsaista $(66 \mathrm{kpl})$ vain yhdellä raemaisen ruokintaryhmän porsaalla todettiin mahahaava. Vieroitusikäisillä porsailla mahahaavan limakalvovauriot olivat rae-ruokintaryhmässä 
yleisempiä valkoisten rotujen porsailla kuin Duroc-risteytysporsailla $(\mathrm{p}=0,002)$. Vilja-puolitiiviste ryhmässä rotujen välinen ero ei yltänyt aivan merkitsevälle tasolle $(\mathrm{p}=0,06)$.

Aikaisemmissa Hyvinkäällä tehdyissä ruokintakokeissa ei ole seurattu vieroitusikäisten porsaiden mahahaavaisuutta, mutta aikaisemmissa kokeissa on todettu, että välityskokoisten porsaiden mahahaavaisuus on rakeistetulla ruokinnalla yllättävän yleistä (39 \%:lla lopetetuista 7-8 viikon ikäisistä porsaista, Karhapää ym. 2009). Tässä kokeessa välityskokoisilla porsailla oli huomattavasti vähemmän mahahaavoja kuin aikaisemmissa kokeissa. Vilja-puolitiiviste-rehulla ruokituilla porsailla vain 3 $\%$ porsaista $(1 / 33 \mathrm{kpl})$ oli mahahaava, kun taas rakeistetulla rehulla ruokituilla mahahaavaa esiintyi 15 \%:lla porsaista. Ero mahalaukun limakalvovaurioiden määrässä ruokintaryhmien välillä ei ollut merkitsevä. Wondra ym. (1995) havaintojen mukaan lihasikojen mahalaukun keratinisoituminen ja haavaumat lisääntyivät, jos rehu oli rakeistettu tai rehun jauhatusaste kasvoi. Mahalaukkumuutokset eivät kuitenkaan vaikuttaneet lihasikojen kasvuun, vaan itse asiassa rehun hyötysuhde parani samalla kun mahalaukkumuutosten vakavuus lisääntyi.

\section{Johtopäätökset}

Pahnueaikana porsaat söivät enemmän rakeistettua rehua kuin vilja-puolitiiviste-rehua ja rakeista rehua syöneet porsaat myös kasvoivat nopeammin. Välikasvatusvaiheessa vilja-puolitiiviste-rehua syöneet porsaat kasvoivat vähän nopeammin kuin rae-rehua syöneet porsaat. Rakeistettua rehua syöneillä porsailla oli välikasvatusosastolla huonompi rehuhyötysuhde kuin vilja-puolitiiviste-rehua syöneillä porsailla.

Rakeistetulla rehulla ruokituilla vieroitetuilla porsailla oli merkitsevästi enemmän mahalaukun limakalvovaurioita kuin vilja-puolitiiviste-rehulla ruokituilla porsailla. Duroc-risteytysporsailla vaurioita oli vähemmän kuin valkoisten rotujen risteytysporsailla. Välityskokoisilla, vilja-puolitiivisterehulla ruokituilla porsailla vain $3 \%$ :lla porsaista oli mahahaava, rakeistetulla rehulla ruokituilla porsailla $15 \%:$ :lla todettiin mahahaava.

Porsaiden ensirehun tekemiseen tarkoitettuja tiivisteitä ei ole juuri markkinoilla. Tässä kokeessa käytetty puolitiiviste oli tarkoitettu isommille välikasvatusporsaille ja se oli ravintoainekoostumukseltaan vaatimattomampi kuin kaupallinen prestartteri. Vilja-puolitiiviste-rehu on halvempi vaihtoehto kuin rakeinen pikkuporsasrehu, tosin tässä kokeessa vilja-puolitiiviste-rehua syöneiden porsaiden kasvu pahnueaikana myös oli hieman hitaampaa. Ongelmia vilja-puolitiiviste-rehun tarjoamiseen aiheuttaa rehun holvaantuminen rehuautomaateissa. Syöntitauot automaattien reistaillessa ovat myös riski mahahaavaumille.

\section{Kirjallisuus}

Algers, B., Jensen, P., \& Steinwall, L. 1990. Behaviour and weight changes at weaning and regrouping of pigs in relation to teat quality. Appl. Anim. Behav. Sci. 26: 143-155.

Chiba L.I. 1994. Effects of nutritional history on the subsequent and overall growth performance and carcass traits of pigs. Livest. Prod. Sci. 41: 151-161.

Gamble, T., Chamberlain, C., Merriman, M. \& Lidwall, R. 1967. Effects of pelleting, pasture and selected diet ingredients on the incidence of esophagogastric ulcers in swine. J. anim. Sci. 26: 1054-1058.

Guise, H.J., Carlyle, W.W.H., Penny, R.H.C., Abbott, T.A., Riches, H.L. \& Hunter E.J. 1997. Gastric ulcers in finishing pigs: Their prevalence and failure to influence growth rate. Vet. Rec. 141:563-566.

Hautala, M. \& Rautiainen, E. 1991. A comparative study of feeder pig units using dry liquid feeding in the western part of Finland. Part 2: Assessment and categorization of the gastric lesions in pigs. Suomen Eläinlääkärilehti 97: 298-307.

Karhapää, M., Siljander-Rasi, H., Fossi, M. \& Partanen, K. 2009. Porsasrehun viljavalinnan ja raekoon vaikutukset mahan ja suoliston terveyteen. (Loppuraportti 26.2.2009).

Nielsen, E. K. \& Invartsen, K. L. 2000. Effect of cereal type, disintegration method and pelleting on stomach content, weight and ulcers and performance in growing pigs. Livest. Prod. Sci. 66: 271-282.

Ritchie, H.D., Luecke, R.W., Baltzer, B.V., Miller, E.R., Ullrey D.E. \& Hoefer, J.A. 1963. Copper and zinc interrelationships in the pig. J. Nutrition, 79: 117-123.

Robertson, I.D., Accioly J.M., Moore K.M., Driesen, S.J., Pethick, D.W. \& Hampson, D.J. 2002. Risk factors for gastric ulcers in Australian pigs at slaughter. Prev. Vet. Med. 53:293-303.

Wondra K.J., Hancock J.D., Behnke K.C., Hines R.H. \& Stark C.R. 1995. Effects of particle size and pelleting on growth performance, nutrient digestibility, and stomach morphology in finishing pigs. J. Anim. Sci. 73:757-763. 